\title{
Identification of drug-resistant Salmonella from food handlers at the University of Gondar, Ethiopia
}

Legesse Garedew-Kifelew ${ }^{1 *}$, Nishanwork Wondafrash ${ }^{1}$ and Amsalu Feleke ${ }^{2}$

\begin{abstract}
Background: Salmonella species are among the most common food borne pathogens worldwide and their infection is one of the major global public health problems. During the last decade, multidrug-resistant Salmonella species have increased to a great deal, especially in developing countries. The prevalence and antimicrobial susceptibility pattern of Salmonella isolates among food handlers at the University of Gondar, Ethiopia, were described in the current investigation.

Method: A cross-sectional study was conducted from February to June, 2013 at the University of Gondar. Stool samples from selected volunteer food handlers were collected and analyzed complemented with questionnaire. Standard isolation, identification and biochemical tests were performed to identify Salmonella isolates. Antimicrobial susceptibility tests were also carried out on each isolate using Kirby-Bauer disc diffusion method. The data was entered into Epi info version 3.5.4 and analyzed using SPSS version 21.

Result: Out of 423 food handlers participated, 303(71.6\%) were females. Almost two-third (71.4\%) of food handlers had no previous medical checkup to Salmonella infection and only 24(5.7\%) of them were certified as food handlers. Thirteen (3.1\%) food handlers were found to be positive for Salmonella isolates. The results of antimicrobial susceptibility test in the current research revealed that from a total of 13 isolates; $9(69.2 \%), 8(61.5 \%), 6(46.2 \%)$ and $6(46.2 \%)$ of the isolates were resistant to amoxicillin, ampicillin, nitrofurantoin and tetracycline, respectively. In addition, nearly half (46.2\%) of the isolates were multidrug-resistant. However; all of them were sensitive for both ceftriaxone and gentamycin.

Conclusion: This study indicated that drug resistant including multidrug-resistant Salmonella isolates were circulating among food handlers at the University of Gondar. These Salmonella positive food handlers pose significant risk of infection to the university community particularly to the student population. It is essential to implement food handlers training on food safety, conduct periodic medical screening and continuous monitoring of food handlers at the study university.
\end{abstract}

Keywords: Antimicrobial susceptibility, Food handlers, Prevalence, Salmonella, Ethiopia

\footnotetext{
* Correspondence: legesse_lg@yahoo.com

'University of Gondar, Faculty of Veterinary Medicine, Gondar, Ethiopia

Full list of author information is available at the end of the article
} 


\section{Background}

Infection due to Salmonella is a public health problem both in developed and in developing countries. WHO estimated that, globally 3 million Salmonella associated deaths have been annually reported. Salmonella infection most commonly occurs in countries with poor standards of hygiene in food preparation, handling and sewage disposal [1].

Food borne salmonellosis often follows consumption of contaminated animal products, fruits and vegetables as well as contamination through unclean work surfaces used to prepare foods. Food can also be contaminated by food handlers who do not thoroughly wash their hands with soap after handling raw foods or after using the bathroom. The carrier states of humans are of concern to the food manufacturing and food service institutions because of the risk of contamination of food [2].

The widespread nature of salmonellosis and the spread of antibiotic resistance are of major concern for both developed and developing countries. An example of the global threat of antibiotic resistance is the multidrugresistant (MDR) Salmonella, resistant for three or more antimicrobial classes. MDR isolates have been widely reported in Europe and America from travelers and adopted children [3]. MDR in both the hospital and community environment are important concern to the clinician, patients and the pharmaceutical industries. Antimicrobial drugs misuse, drugs prescription without susceptibility test, self-medication and long duration of hospitalization was suggested to augment the problem of MDR in developing nations [4].

The true incidence of salmonellosis in humans is difficult to evaluate because of lack of an epidemiological surveillance system in different areas, particularly in developing countries. But a few studies indicated the widespread occurrence and distribution of Salmonella in Ethiopia. According to reports [5-7], in recent years the number of out breaks of Salmonella in humans and its antimicrobial resistance has increased considerably in the country. Despite the challenge, research conducted about food salmonellosis among food handlers and its antimicrobial susceptibility pattern is scarce in Ethiopia particularly in Gondar. Therefore; this research was initiated to determine the prevalence and antimicrobial susceptibility pattern of Salmonella isolates among food handlers working at the University of Gondar students' dining rooms to recommend appropriate prevention and control measures.

\section{Methods}

\section{Study area}

The study was carried out on food handlers (those participated in food preparation, dispatch, store and related services) of University of Gondar students' dining rooms in all campuses. Laboratory investigation was done in the Veterinary Public Health and Microbiology Laboratory, University of Gondar. The University has a latitude and longitude of $12^{\circ} 36^{\prime} \mathrm{N} 37^{\circ} 28^{\prime} \mathrm{E}$ with an elevation of 2133 meters above sea level and located $730 \mathrm{~km}$ north of Addis Ababa [8]. University of Gondar currently enrolled more than 26,000 students out of which more than half of them are getting dining services in the dining rooms included in this study. A total of 664 food handlers are working in these students dining rooms.

\section{Sample size determination and sampling procedure}

The sample size was determined by using a single population proportion formula [9] considering the following assumptions: $Z \alpha / 2=1.96$ for the standard scale of $95 \%$ level of confidence, level of precision $=5 \%, \mathrm{P}=0.5$

$$
\begin{aligned}
& \mathrm{n}=\frac{\mathrm{P}(1-\mathrm{p})(\mathrm{Z} \alpha / 2)^{2}}{\mathrm{~d}^{2}} \\
& \mathrm{n}=\frac{(1.96)^{2} \times 0.5(1-0.5)}{(0.05)^{2}}=384
\end{aligned}
$$

The total sample size was 423 with $10 \%$ non response rate included.

\section{Sampling and data collection procedure}

Simple random sampling using lottery method was used to select the study subjects. Complete list of food handlers was obtained from human resource management of University of Gondar. Socio-demographic data was gathered by using structured pretested questionnaire and face to face interview. Stool specimens were collected from food handlers with a suitable labeled wide-mouthed plastic container and clean wooden applicator stick. Specimens were immediately transported to laboratory using ice box.

\section{Bacteriological examination}

Bacteriological examination was carried out based on standard procedures previously described [10]. Briefly: twenty five grams of stool sample was homogenized in $225 \mathrm{ml}$ of buffered peptone water (BPW, Oxoid, England) within a sterile stomacher bag. The homogenate was mixed well using a laboratory blender (Stomacher 400, Seward, England) for 1 minute and incubated for 24 hours at $37^{\circ} \mathrm{C}$. Then, $1 \mathrm{ml}, 1 \mathrm{ml}$ and $0.1 \mathrm{ml}$ aliquot of the enrichment broths was transferred aseptically into $10 \mathrm{ml}$ of Selenite Cystine (SC), $10 \mathrm{ml}$ of Tetrathionate (T) and $10 \mathrm{ml}$ of Rappaport-Vassilliadis (RV) broth, and incubated for 24 hours at $37^{\circ} \mathrm{C}, 37^{\circ} \mathrm{C}$ and $42^{\circ} \mathrm{C}$, respectively. Following incubation, a loopful of each culture was streaked onto Brilliant Green Agar (BGA, Oxoid, England) and Xylose Lysine Deoxycholate (XLD, Oxoid, England) agar 
plates and incubated at $37^{\circ} \mathrm{C}$ for 24 to 48 hours. The plates (BGA and XLD) were examined for the presence of characteristics Salmonella colonies. A single positive colony showing red color with a black center on XLD and red color on BGA agars were subjected for biochemical tests for confirmation.

\section{Biochemical tests}

Identification of Salmonella was performed by subjecting presumptive colonies onto Triple Sugar Iron (TSI) agar, Lysine Iron agar, Methyl Red (MR) broth, VogesProskauer (VP) broth, Urea broth, Indole test, and Citrate utilization tests and incubated for 24 to 48 hours at $37^{\circ} \mathrm{C}$. Colonies producing an alkaline slant with acid butt and hydrogen sulfide production on TSI, positive for lysine, negative for urea hydrolysis, negative for Indole test, negative for VP, positive for citrate utilization and positive for MR test were considered to be Salmonella [10]. Finally, all of the confirmed Salmonella isolates were examined for antimicrobial susceptibility.

\section{Antimicrobial susceptibility test}

All isolates were tested by Kirby-Bauer disk diffusion method using guidelines established by the Clinical and Laboratory Standards Institute (CLSI) [11]. In brief, by taking pure isolated colonies, bacterial suspension in test tubes was adjusted and compared to $0.5 \mathrm{McF}$ Farland turbidity standards. The diluted bacterial suspension was then transferred to Mueller-Hinton agar plate using a sterile cotton swab and the plate was seeded uniformly by rubbing the swab against the entire agar surface followed by 24 hours incubation. Antibiotic impregnated discs were then applied to the surface of the inoculated plates using sterile forceps. The plates were then incubated aerobically at $37^{\circ} \mathrm{C}$ for 24 hours. E. coli (ATCC 25922), which was susceptible to all tested drugs, was used for quality control. A total of 9 selected antibiotic disks (Oxoid, UK) including amoxicillin (AML) $2 \mu \mathrm{g}$, ampicillin (AMP) $10 \mu \mathrm{g}$, cephalothin (KF) $30 \mu \mathrm{g}$, ceftriaxone $(\mathrm{CRO}) 30 \mu \mathrm{g}$, gentamicin $(\mathrm{CN}) 10 \mu \mathrm{g}$, nalidixic Acid (NA) $30 \mu \mathrm{g}$, sulphamethoxazole-trimetoprime (SXT) $25 \mu \mathrm{g}$, teteracycline (TE) $30 \mu \mathrm{g}$ and nitrofurantoin (F) $100 \mu \mathrm{g}$ were applied. Finally, the zone of inhibition was measured including the disk diameter and the susceptible, intermediate and resistant categories were assigned on the basis of the critical points recommended by the CLSI.

\section{Study variables}

Prevalence of Salmonella and their antimicrobial susceptibility patterns were dependent variables whereas sex, age, educational background, service year, hand washing habit, periodical medical examination, and food hygiene training status were independent variables considered in the current study.

\section{Data processing and analysis}

Data were cleaned and entered using Epi-Info version 3.5.4. The data then was transferred and analyzed using SPSS version 21. Descriptive statistics such as percentage were applied to compute the data.

\section{Ethical consideration}

Ethical clearance was obtained from Institutional Review Board of Institute of Public Health, College of Medicine and Health Sciences, University of Gondar. Written informed consent was obtained from all study participants.

\section{Results}

\section{Socio-demographic characteristics of the study} participants

Overall, 423 food handlers were participated in this study with mean age and standard deviation of $33.5 \pm$ 10.5. Three hundred three $(71.6 \%)$ of the participants were females. Of the total participants, 24(5.7\%), 248(58.6\%) and $151(35.7 \%)$ of them were trained and certified, trained but not certified and received no training for food preparation and handling, respectively. Regarding regular periodical medical examination for infectious diseases, only 121 (28.6\%) was confirmed taking periodical medical checkup. Evaluation of their service year in dining rooms indicated that $326(77.1 \%)$ food handlers had 2-9 years of services.

\section{Salmonella infection status of food handlers}

Stool specimens examination revealed that 13(3.1\%) out of 423 participants were infected with Salmonella. All of the infected food handlers were females. The highest proportion of infection (4.2\%) across age was within the age group of 28-37 years. Of the total Salmonella positives, $10(76.9 \%)$ were from formally educated group and the highest level of infection (53.8\%) was associated with 1-4 grade level as tabulated in Table 1.

The isolation rate of Salmonella was higher among food handlers who served in the students' dining rooms for a period of $\leq 1$ years $(6.7 \%)$ since most of them were not trained in food handling and preparation formally. From a total of 302 food handlers who never undergone periodical medical check-up for the common infectious diseases, 11(3.6\%) were Salmonella positives. Relatively higher Salmonella prevalence was detected in those who did not undertake periodical medical check-up. In addition, those who did not have hand washing habit after using toilet, after touching dirty materials and before starting preparation of food were risk groups from whom relatively higher prevalence of Salmonella was recorded. 
Table 1 Prevalence of Salmonella among food handlers at the University of Gondar

\begin{tabular}{|c|c|c|c|}
\hline \multicolumn{2}{|l|}{ Variables } & $\begin{array}{l}\text { Total } \\
\text { tested } \\
\text { Number (\%) }\end{array}$ & $\begin{array}{l}\text { Salmonella } \\
\text { positive } \\
\text { Number (\%) }\end{array}$ \\
\hline \multirow[t]{5}{*}{ Age-group } & $18-27$ years & $134(31.7 \%)$ & $4(3 \%)$ \\
\hline & 28-37 years & $143(33.8 \%)$ & $6(4.2 \%)$ \\
\hline & $38-47$ yeas & $101(23.9 \%)$ & $0 \%$ \\
\hline & $48-57$ years & $38(8.9 \%)$ & $2(5.3 \%)$ \\
\hline & $>58$ years & $7(1.7 \%)$ & $1(14.3 \%)$ \\
\hline \multirow[t]{2}{*}{ Sex } & Male & 303 & $13(4.3 \%)$ \\
\hline & Female & 120 & $0(0.0 \%)$ \\
\hline \multirow[t]{6}{*}{ Educational background } & $\begin{array}{l}\text { Cannot read } \\
\text { and write }\end{array}$ & $11(2.6 \%)$ & $1(9.1 \%)$ \\
\hline & $\begin{array}{l}\text { Read and } \\
\text { write only }\end{array}$ & $36(8.5 \%)$ & $2(5.6 \%)$ \\
\hline & 1-4 grades & $163(38.5 \%)$ & $7(4.3 \%)$ \\
\hline & 5-8 grades & $113(26.7 \%)$ & $0(0 \%)$ \\
\hline & $9-12$ grades & $95(22.5 \%)$ & $3(3.2 \%)$ \\
\hline & $>12$ grades & $5(1.2 \%)$ & $0(0 \%)$ \\
\hline \multirow{2}{*}{$\begin{array}{l}\text { Periodical medical } \\
\text { check-up }\end{array}$} & Yes & 121 & $2(1.6 \%)$ \\
\hline & No & 302 & $11(3.6 \%)$ \\
\hline \multirow{3}{*}{$\begin{array}{l}\text { Service year in dining } \\
\text { rooms }\end{array}$} & $\leq 1$ year & 45 & $3(6.7 \%)$ \\
\hline & 2-9 years & 326 & $8(2.4 \%)$ \\
\hline & $10^{+}$years & 52 & $2(3.9 \%)$ \\
\hline \multirow{2}{*}{$\begin{array}{l}\text { Hand washing habit after } \\
\text { using a toilet by water only }\end{array}$} & Yes & 318 & $7(2.2 \%)$ \\
\hline & No & 105 & $6(5.7 \%)$ \\
\hline \multirow{2}{*}{$\begin{array}{l}\text { Hand washing habit before } \\
\text { preparing food }\end{array}$} & Yes & 301 & $5(1.7 \%)$ \\
\hline & No & 122 & $8(6.6 \%)$ \\
\hline \multirow{2}{*}{$\begin{array}{l}\text { Hand washing habit after } \\
\text { touching dirty materials }\end{array}$} & Yes & 82 & $3(3.7 \%)$ \\
\hline & No & 341 & $10(2.9 \%)$ \\
\hline \multirow{2}{*}{$\begin{array}{l}\text { Hand washing habit after } \\
\text { using a toilet by soap and } \\
\text { water }\end{array}$} & Yes & 272 & $4(1.5 \%)$ \\
\hline & No & 151 & $9(7.4 \%)$ \\
\hline
\end{tabular}

\section{Antimicrobial susceptibility patterns of Salmonella isolates}

Of the 13 Salmonella isolates subjected to antimicrobial susceptibility test using a panel of 9 different antimicrobials, 6(46.2\%) were multidrug-resistant. On the other hand, all of the isolates were susceptible for both ceftriaxone and gentamycin. Majority of the isolates $11(84.6 \%)$ were also sensitive to nalidixic acid and sulphamethoxazole-trimetoprime. But none of the Salmonella isolates identified was sensitive to all antimicrobial agents tested. This indicated that all of the isolates were resistant at least to one antimicrobial agent. The highest resistance was exhibited by 9(69.2\%), 7(54.8\%), $6(46.2 \%)$ and $6(46.2 \%)$ of the isolates for amoxacillin, ampicillin, tetracycline and nitrofurantoin, respectively, as shown in Tables 2 and 3.
Table 2 Antimicrobial susceptibility patterns of Salmonella isolates from food handlers

\begin{tabular}{llll}
\hline Antimicrobials $(\boldsymbol{\mu g})$ & \multicolumn{3}{l}{ Antibiotic susceptibility patterns } \\
\cline { 2 - 4 } & $\begin{array}{l}\text { Sensitive } \\
\mathbf{N}(\%)\end{array}$ & $\begin{array}{l}\text { Intermediate } \\
\mathbf{N}(\%)\end{array}$ & $\begin{array}{l}\text { Resistant } \\
\mathbf{N}(\%)\end{array}$ \\
\hline Amoxacillin $\left(\mathrm{AML}_{2}\right)$ & $3(23.1 \%)$ & $1(7.7 \%)$ & $9(69.2 \%)$ \\
Ampicillin $\left(\mathrm{AMP}_{10}\right)$ & $4(30.8 \%)$ & $2(15.4 \%)$ & $7(54.8 \%)$ \\
Cephalothin $\left(\mathrm{KF}_{30}\right)$ & $5(38.5 \%)$ & $3(23 \%)$ & $5(38.5 \%)$ \\
Ceftriaxone $\left(\mathrm{CRO}_{30}\right)$ & $13(100 \%)$ & $0(0 \%)$ & $0(0 \%)$ \\
Gentamicin $\left(\mathrm{CN}_{10}\right)$ & $13(100 \%)$ & $0(0 \%)$ & $0(0 \%)$ \\
Nalidixic acid $\left(\mathrm{NA}_{30}\right)$ & $11(84.6 \%)$ & $0(0 \%)$ & $2(15.4 \%)$ \\
Sulphamethoxazole-trimetoprim & $11(84.6 \%)$ & $0(0 \%)$ & $2(15.4 \%)$ \\
(SXT 25$)$ & & & \\
Tetracycline $\left(\mathrm{TE}_{30}\right)$ & $7(53.8 \%)$ & $0(0 \%)$ & $6(46.2 \%)$ \\
Nitrofurantoin $\left(\mathrm{F}_{100}\right)$ & $7(53.8 \%)$ & $0(0 \%)$ & $6(46.2 \%)$ \\
\hline
\end{tabular}

\section{Discussion}

The current study documented that $3.1 \%$ of food handlers had Salmonella infection which is consistent with 3.4\% reported from Addis Ababa [12] and 2.3\% from Ghana [13]. However; this was lower than 7\% [14], 13.63\% [15], and 18\% [16] prevalence from Jakarta (Indonesia), Addis Ababa (Addis Ababa), and Nigeria, respectively. The lower prevalence rate in the present study might be due to the fact that food handlers in University of Gondar had a better habit of hand washing after using a toilet and before handling of food than food handlers participated in other studies aforementioned above.

On the other hand, lower prevalence rates of Salmonella infection were reported from different studies compared to this study. In these reports there were no Salmonella infection among food handlers working in a student's

Table 3 Drug resistance profile of Salmonella isolates from food handlers

\begin{tabular}{lll}
\hline Resistance profile & $\begin{array}{l}\text { No of isolates with } \\
\text { resistance profile }\end{array}$ & Resistance category \\
\hline AML, AMP, NA, SXT, TE & 1 & Multidrug resistant \\
AML, AMP, SXT, TE, F & 1 & Multidrug resistant \\
$A M L, A M P, T E, F$ & 1 & Multidrug resistant \\
AML, KF, NA, F & 1 & Multidrug resistant \\
$A M L, A M P, K F$ & 2 & Drug resistant \\
$A M P, T E, F$ & 2 & Multidrug resistant \\
$A M L, A M P$ & 1 & Drug resistant \\
$A M L, K F$ & 1 & Drug resistant \\
$A M L, F$ & 1 & Drug resistant \\
$K F$ & 1 & Drug resistant \\
$T E$ & 1 & Drug resistant \\
\hline
\end{tabular}

Key: $\mathrm{AML}=$ Amoxacillin, $\mathrm{AMP}=$ Ampicillin, $\mathrm{F}=$ Nitrofurantoin, $\mathrm{KF}=$ Cephalothin, $\mathrm{CRO}=$ Ceftriaxone, $\mathrm{SXT}=$ Sulphamethoxazole-trimetoprime, $\mathrm{TE}=$ Tetracycline, $\mathrm{NA}=$ Nalidixic Acid, $\mathrm{CN}=$ Gentamycin. 
cafeteria of University of Gondar and Gondar Teachers Training Collage [17], in food workers of Turkey [18], in food handlers at Hawassa [5], and food workers in a medical college in North India [19]. In another studies, 0.93\% and $0.03 \%$ Salmonella infection rates were recorded from Northern Ethiopia asymptomatic food handlers [20] and amongst food workers in hotels, supermarket, food factories, and restaurants in Japan [21], respectively. The sample size and personal hygiene differences of the food handlers might help to explain this discrepancy.

The high prevalence of Salmonella in the age group of 18-37 years in the present study was comparable with a study conducted in Addis Ababa [12]. This might be due to the fact that the chronic Salmonellae carrier state occurs most commonly among middle age women [22]. In addition, the prevalence of Salmonella infection was higher in females in the current investigation; supported by the previous studies in Ethiopia [12] and Ghana [13].

The results of antimicrobial susceptibility test in the current research revealed that nearly half of $(46.2 \%)$ the isolates were multidrug-resistant according to the recent drug-resistance definition [23]. In addition, all of the Salmonella isolates were resistant for at least one or more drugs tested. Further analysis of antimicrobial susceptibility test results showed that $69.2 \%$ of Salmonella isolates were resistant to Amoxicillin which conform a report from Nigeria [16] that proved Salmonella species in recent years have become progressively more resistant to clinically useful antibiotics including Amoxicillin. The resistant nature of Salmonella isolates to Amoxicillin might be ascribed to high level of utilization of this drug due to its relatively cheaper price and readily available nature to the local community in the current study area. This might create the opportunity for misuse of this drug thus heralding the emergence of resistant strains of Salmonella. Furthermore, 54.8\% Salmonellae isolates were resistant to ampicillin. This finding was in agreement with findings from Jimma and Addis Ababa that reported 54\%, [6] and 59.4\% [7] resistant isolates, in that order. But this ampicillin resistance pattern of Salmonella isolated during this study was lower from reports that indicated $100 \%$ [15] and 82.3\% [24] resistance in Addis Ababa isolated from dairy farm attendant and pediatric patients, respectively. Furthermore; the current result was lower than $87.5 \%, 100 \%$, and $91.8 \%$ of ampicillin resistant Salmonella isolates reported from Addis Ababa [12], Bahir Dar [25] and Tamil Nadu [26], respectively.

The $46.2 \%$ tetracycline resistant Salmonella isolates registered in our research was in agreement with 46.9\% [7], but higher than 33.3\% [15] resistance reports from Addis Ababa. Yet it is by far lower than $92.9 \%$ resistance disclosed from USA [27]. Tetracycline is the most frequently prescribed drug in the current study area including for other infectious diseases both in human and veterinary medicine that could also be mentioned as one of the reasons for the development of such a higher resistance. A worrying aspect of the current result is that it will also be difficult to treat other clinical infectious cases using tetracycline. Although the resistance pattern of Salmonella isolates from food handlers for sulphamethoxazoletrimetoprim in this study is low (15.4\%), previous studies have documented much higher [24,7] and lower [15] resistance rates from Ethiopia in different times.

Interestingly, all of the Salmonella isolates in the current investigation were susceptible to gentamycin and ceftriaxone, which is in agreement with similar studies in Lagos [28] and Ethiopia [12]. This result was higher than 75\% [15] and 19.8\% [7] susceptibility reports for gentamycin and 78.8\% [7] for cetriaxone from Addis Ababa. ceftriaxone is relatively recently introduced and more costly drug compared to cephalothin in the current study area. Due to this, the community might have used it less frequently that contributed for the low rate of resistance recorded. Good efficacy was also observed in nalidixic acid in which $84.6 \%$ of the isolates were susceptible that was nearly in line with the study conducted in Lagos, Nigeria [28] and Tamil Nadu, India [29]. In contrast, a study conducted in Ghana revealed resistance to nalidixic at a higher level [30]. These differences to nalidixic acid efficacy might be due to presence or absence of previous exposure of isolates to the drug in other countries than this study area or it might be due to the fact that nalidixic acid is costly and only rarely prescribed in our study area. On the other hand, $46.2 \%$ of the isolates exhibited resistance to nitrofurantoin, which is higher than $15 \%$ resistance profile reported from Addis Ababa [15].

\section{Conclusion}

Drug resistant including multidrug-resistant Salmonella isolates are circulating among food handlers at the University of Gondar posing high risk of infection for the University community having close contact with those carriers. Programmed medical checkup for food handlers with respect to infectious diseases was not practiced at the University. Health education and check-up, and immediate appropriate treatment strategy for positives based on in-vitro antimicrobial susceptibility tests should be in place. Further in-depth serotyping and drug resistant gene identification should be carried out.

\section{Competing interest}

The authors declare that they have no competing interests.

\section{Authors' contributions}

LG carried out the conception of the research idea and design the methodology, laboratory work, data analysis and interpretation and preparation of the manuscript for publication. NW carried out the laboratory work, data collection and analysis and reviewed of the manuscript. AF reviewed the manuscript. All authors' read and approved the final manuscript. 


\section{Authors' information}

Authors are human and animal health professionals and members of Zoonosis and Food Safety research team at the University of Gondar. They are engaged and interested in Zoonotic Food-borne Pathogens and Food Safety research.

\section{Acknowledgements}

University of Gondar is greatly acknowledged for all rounded technical assistance for the smooth accomplishment of this research. The authors acknowledge Dr. Reta Tesfaye from the University of Gondar, for his suggestions and proofreading the manuscript.

\section{Author details}

${ }^{1}$ University of Gondar, Faculty of Veterinary Medicine, Gondar, Ethiopia.

${ }^{2}$ University of Gondar, Institute of Public Health, Gondar, Ethiopia.

Received: 22 March 2014 Accepted: 21 July 2014

Published: 18 August 2014

\section{References}

1. World Health Organization (WHO): Food Safety-Food borne diseases and value chain management for food safety. In "Forging links between Agriculture and Health" CGIAR on Agriculture and Health Meeting. Geneva, Switzerland: World Health Organization; 2007.

2. World Health Organization (WHO): World Health Organization global strategy for food safety: safer food for better Health. Geneva, Switzerland: World Health Organization; 2002.

3. Hendriksen RS, Mikoleit M, Kornschober C, Rickert RL, Duyne SV, Kjelso C, Hasman H, Cormican M, Mevius D, Threlfall J, Angulo FJ, Aarestrup FM: Emergence of Multidrug-Resistant Salmonella Concord Infections in Europe and the United States in Children Adopted From Ethiopia, 2003-2007. Pediatr Infect Dis J 2009, 28:814-818.

4. Hohmann EL: Nontyphoidal Salmonellosis. Clin Infect Dis 2001, 32:263-269.

5. Desta M: Prevalence of Salmonella and Shigella among Food Handlers in Catering Establishments in Hawassa University, Hawassa, Ethiopia. In MSC thesis. Addis Ababa, Ethiopia: Addis Ababa University; 2010.

6. Misganaw B, David W: A Study of Salmonella Carriage among Asymptomatic Food-Handlers in Southern Ethiopia. Int J Nutr Food Sci 2013, 2(5):243-245.

7. Zewdu E, Cornelius P: Antimicrobial resistance pattern of Salmonella serotypes isolated from food items and personnel in Addis Ababa. Ethiopia Trop Anim Health Prod 2009, 41(2):241-249.

8. CSA (Central Statistical Authority): Central Statistical Investigatory: Statistical Report. Addis Ababa, Ethiopia: Central Statistical Authority, Federal Democratic Republic of Ethiopia; 2003.

9. Thrusfield M: Diagnostic Testing. In Veterinary Epidemiology. 3rd edition. Cambridge, USA: Black Well Science Ltd; 2005:228-246.

10. World Health Organization (WHO): Basic Laboratory Procedures in Clinical Bacteriology. 2nd edition. Geneva, Switzerland: World Health Organization; 2003:37-50.

11. CLSI (Clinical and Laboratory Standards Institute): Performance for antimicrobial disk susceptibility tests; approved standard, Volume 32(1). 11th edition. Wayne, USA: CLSI document M02-A11; 2012:1-76.

12. Getnet F: Isolation of Salmonella Species Among apparently healthy food handlers of Addis ababa university students-cafteria. In MSc thesis. Addis Ababa, Ethiopia: Addis Ababa University; 2011.

13. Feglo PK, Frimpong EH, Essel-Ahun M: Salmonellae carrier status of food vendors in Kumasi, Ghana. East Afr Med J 2004, 81:358-361.

14. Vollaard AM, Ali S, Van Asten HAGH, Ismid IS, Widjaja S, Visser LG: Risk factors for transmission of foodborne illness in restaurants and street vendors in Jakarta. Indo Epid Infect 2004, 132:863-872.

15. Addis Z, Kebede K, Sisay Z, Alemayehu H, Yirsaw A, Kassa T: Prevalence and antimicrobial resistance of Salmonella isolated from lactating cows and in contact humans in dairy farms of Addis Ababa: a cross sectional study. BMC Infect Dis 2011, 11:1-7.

16. Okojie $\mathrm{OH}$, Wagbatsoma VA, Ighoroge $\mathrm{AD}$ : An assessment of food hygiene among food handlers in a Nigerian University campus. Nigerian Post-grad Med J 2005, 12(2):93-96.

17. Andargie G, Kassu A, Moges F, Tiruneh M, Huruy K: Prevalence of bacteria and intestinal parasites among food handlers in Gondar Town, Northwest Ethiopia. J Health Popul Nutri 2008, 26(4):451-455.
18. Pala K, Ozakin C, Akis N, Sinirtas M, Gediko S, Aytekin H: Asymptomatic carriage of bacteria in food workers in Nilüfer district, Bursa, Turkey. Turk J Med Sci 2010, 40(1):133-139.

19. Khurana S, Taneja N, Thapar R, Sharma M, Malla N: Intestinal bacterial and parasitic infections among food handlers in a tertiary care hospital of North India. Trop Gastroenterol 2008, 29:207-209.

20. Zeru K, Kumie A: Sanitary conditions of food establishments in Mekelle town,Tigray, North Ethiopia. Ethiop J Health Dev 2007, 21(1):3-11.

21. Murakami K, Ishihara T, Horikawa K, Oda T: Features of Salmonella serovars among food handlers in Kyushu, Japan. New Microbiological 2007, 30:155-159.

22. Center for Disease Control and Prevention (CDC): Center for Disease Control and Prevention (CDC). Food Borne Illness Annual Report 2005, 1:1-13. CDC, USA.

23. Magiorakos AP, Srinivasan A, Carey RB, Carmeli Y, Falagas ME, Giske CG, Harbarth S, Hindler JF, Kahlmeter G, Olsson-Liljequist B, Monnet DL, Paterson DL, Rice LB, Stelling M, Struelens J, Vatopoulos A, Weber JT: Multidrugresistant, extensively drug-resistant and pandrug-resistant bacteria: An international expert proposal for interim standard dentitions for acquired resistance. Clin Microbiol Infect 2012, 18:268-281.

24. Beyene B, Asrat D, Mengistu Y, Aseffa A, Wain J: Typhoid fever in Ethiopia. J Infect Developing Countries 2008, 2(6):448-453.

25. Abera B, Biadegelgen F, Bezabih B: Prevalence of Salmonella typhi and intestinal parasites among food handlers in Bahir Dar Town, Northwest Ethiopia. Ethiop J Health Dev 2010, 24(1):46-50.

26. Valli A, Selvan N, Sudha A, Dhananjeyan V, Iyappan P: Screening of asymptomatic typhoid carriers from nail samples from roadside foodhandlers in Tamil Nadu, India. Current Res Bacterio/ 2010, 3:238-244.

27. Nkuchia M, M'ikanatha NM, Sandt CH, Localio AR, Tewari D, Rankin SC, Whichard JM, Altekruse SF, Lautenbach E, Folster JP, Russo A, Chiller TM, Reynolds SM, McDermott PF: Multidrug-Resistant Salmonella Isolates from Retail Chicken Meat Compared with Human Clinical Isolates. Foodborne Pathog Dis 2010, 7(8):128-213.

28. Smith SI, Bamidele M, Goodluck HA, Rowora MN, Omonigbehn EA, Opere BO: Antimicrobial susceptibilities of Salmonellae isolated from foodhandlers and cattle in Lagos, Nigeria. Int J Health Res 2009, 2:189-193.

29. Senthilkumar B, Prabavaran G: Multidrug resistant Salmonella Typhi in asymptomatic Typhoid carriers among food handlers in Mamakkal District,Tamil nadu.Indian. J Med Microbiol 2005, 23(2):92-94.

30. Robertson FM, Addy ME, Mensah PA, Crupper SS: Molecular characterization of antibiotic resistance in clinical Salmonella Typhi in Ghana. FEMS Microbiol Lett 2002, 215:249-253.

doi:10.1186/1756-0500-7-545

Cite this article as: Garedew-Kifelew et al:: Identification of drug-resistant Salmonella from food handlers at the University of Gondar, Ethiopia. BMC Research Notes 2014 7:545

\section{Submit your next manuscript to BioMed Central and take full advantage of:}

- Convenient online submission

- Thorough peer review

- No space constraints or color figure charges

- Immediate publication on acceptance

- Inclusion in PubMed, CAS, Scopus and Google Scholar

- Research which is freely available for redistribution 